\title{
Actualidad
}

\section{INFECCIONES POR EL VIRUS COXSACKIE}

Pur el De. MANLIEL RODRIGUFZ. IEIVA *

Servicio A de Medicina.-Profa. A. Baeza Goñi y l. Mencghghlo R.

Inspital "M, Arriarín"

En 1948, Dalldorf y Sickles (1) anunciaron el aislamiento de un nuevo microorganismo filtrable proveniente de dos enfermos con un cuadro clínico semejante a la poliomielitis. A este nuevo virus obtenido de las deposiciones de los enfermos en referencia y patógeno para la laucha lactante se le designó "Virus Coxsackie", porque los enfermos de los cuales fué aislado eran de un pueblo del Estado de Nueva York, llamado Coxsackie. Más tarde, como abreviación del nombre se le llamó también "Virus C.".

En 1949, Melnick, Shaw y Curnen (2) publicaron el aislamiento de un virus patógeno para la laucha lactante $y$ proveniente de un enfermo que presentaba un cuadrc clínico semejante al de la poliomielitis de forma no paralítica.

Con posterioridad a estas dos fechas, que marcan la iniciación de un nuevo capítulo en la patología, Curnen en un caso (3); Shaw, Melnick y Curnen (4) en infecciones producidas en el personal del Laboratorio pudieron demostrar la relación existente entre este nuevo microorganismo aislado $y$ el cuadro clínico conocido como pleurodinia infecciosa. Finalmente, Huebner y colaboradores (5) lograron demostrar en procesos febriles agudos de corta duración y en el cuadro descrito por Zahorsky en 1920 (6) y llamado más tarde angina herpética (7), la presencia de un virus filtrable patógeno para la laucha lactante y que pertenecía a este mismo grupo.

Desde 1948, en que Dalldorf hiciera su primera publicación hasta el momento actual, han sido muchas las publicaciones aparecidas en la literatura médica, particularmente Norteamérica, sobre este nuevo grupo de microorganismos, tanto sobre sus caracteres físicos, bioquímicos, inmunológicos y poder patógeno experimental (8) (9) (10) (11) (12) (13) (14), cuanto en el aislaniento a partir de diversos procesos infecciosos, algunos de ellos bien establecidos como la pleurodinia infecciosa (4) (15) (16) (17) y la angina herpética (5) (18); otros en cuyo rol etiológico aún no ha sido bien establecida su participación, comon es el caso de las meningitis asépticas (19) (20) y en los casos de su asociación a cuadros semejantes a la poliomielitis anterior aguda (1) (2) (19) (21) (22) (23) $\mathrm{y}$, finalmente, otros en que como la gripe de verano y las llamadas "fiebres de origen des-

- Felluw of the U. S. Public Health Service. 
conocido" (24) (25) no se ha lozrado establecer bien los caracteres clínicos, etiológi$\cos$ ni epidemiológicos como para darles la importancia de una entidad clínica independiente o sólo como manifestaciones aisladas de un cuadro de infección general a una amplia variedad de un mismo microorganismo.

Por otra parte, ha sido posible aislar el virus repetidamente de lavados bucales (5) (26) de las aguas servidas (2) (27) y de las moscas (2).

Finalmente, estudiando retrospectivamente muestras guardadas en los laboratorios, Weller (15) ha logrado demostrar la etiología a "Virus C" de una epidemia de pleurodinia infecciosa en un brote ocurrido en 1945 en Massachusetts.

Se trata de un grupo de virus múltiples, inmunológicamente considerados, que por su tamaño se ubican dentro de los más pequeños, ya que éste oscila dentro de los 1020 milinicrones. No son inactivados por la penicilina, estreptomicina ni aureomicina $y$ resisten bien la acción del éter. Pueden mantener su infectividad por varios meses a $4^{\circ}$ C y hasta 7 dias a la temperatura ambien1.e. A una temperatura de $-20^{\circ} \mathrm{C}$ a $-70^{\circ} \mathrm{C}$ y en suspensiones en agua destilada, leche descremada o caldo de carne pueden mantener su infectividad por más de 15 meses. Ha sido posible conservarlos por períodos más largos de tiempo en tejido muszular su. mergido en $50 \%$ de glicerina o en suero de monos y a una temperatura de $-70^{\circ} \mathrm{C}$. (10) (14).

Son patógenos para la Jaucha lactante, er las que pueden propagarse por inoculación intracerebral, intraperitoneal, subcutánea y vía oral (10) y aunque la edad óptima de inoculación son los cuatro primeros días de nacidas, se ha logrado propagarlos hasta lo; 12 a 14 días de edad (14) y en açuellas capas de alto título, es posible hacerlas desarrollarse aun en lauchas de 20 días (10).

Han sido inoculados en numerosos hués. pedes, particularmente en monos cynomolgus, utilizando diferentes vías, pero se ha fracasado en la producción de la enfermedad experimental; sin embargo, Melnick y Ladinko (28) han logrado producir el estado de portador $y$ aun fiebres en esta claso de monos alimentados con el virus. Estos animales así estimulados desarrollan a los 12 días anticuerpos que persisten a lo menos
6 meses, período durante el cual no pueden ser reinfectados con la misma cepa.

Huebner (14), usando las cepas $\mathrm{H} 2$ y H3 del grupo A logró producir el estado de portador intestinal y faríngeo en chimpancés. Este mismo autor (29), mediante el traspaso alternado de una cepa del tipo 2 de Dalldorf por saco vitelino y laucha, logró mantenerla a través de $\mathbf{1 0}$ pasajes. Los tejidos embrionarios, después del pasaje $N^{o} 10$, fueron capaces de reproducir los fenómenos paralíticos y la muerte de la laucha lactante, a la cual se le inoculó con una dilución de $10^{-7}$. Pese a estas experiencies aun no ha sido posible en forma práctica aumentar el número de huéspedes susceptibles a este virus.

La enfermedad experimental en Ia laucha lactante puede asumir dos formas o tipos de fenómenos paralíticos: la primera se caracteriza por una parálisis flácida completa de las cuatro extremidades, que generalmente aparece entre el $2^{\circ}-10^{\circ}$ día de inoculadas. Las prineras manifestaciones de enfermedad las constituyen un desinterés por alimentarse, debilidad, tendencia a claudicar de una o de las dos extremidades traseras. establecidas las parálisis la muerte sobreviene dentro de las 24-48 horas siguientes. La segunda forma de la enfermedad que se presenta especialmente en el tipo 1 del grupo A de Dalldorf, se caracteriza por una parálisis de tipo espástico, aun cuando al examen histopatalógico del cerebro no se encuentran lesiones. En los primeros traspasos este tipo de síntomas se inician dentro de los 7-8 días de inoculación. Las primeras manifestaciones se caracterizan por una caida en prono de la extremidad distal de una de las dos extremidades anteriores acompañada de ligera espasticidad, después de varios pasajes las parálisis sobrevienen en forma más rápida y evidente.

Las lesiones histopatológicas de los músculos esqueléticos muestrás una extensa miositis, edema, pérdida de la estriación, semejando estrechamente en sus caracteres a la degeneración de Zenker.

Los núcleos de los segmentos necrosados presentan picnosis y en ciertas zonas marcada cariortexis. En el intersticio se aprecia una marcada infiltración mononuclear.

No se han descitís cuerpos de inclusión.

Las lesiones encontradas en el sistema nervioso central del tipo degenerativo se ubican especialmente eñ el hipocampo, dán- 
dole a ésta un aspecto esponjoso con pérdida total de su arquitectura.

En bases al aspecto histopatológico, que presenta la laucha lactante, este virus ha sido clasificado en dos grandes grupos: A y B. El grupo A se caracteriza por determinar parálisis en la laucha, como el resultado de una extensa miositis, que compromete a todos los músculos esqueléticos. El sistema nervioso central es escasamente comprometido o no presenta ningún compromiso. En el grupo B los virus determinan escasa miositis, pero producen una degeneración quística del cerebro y necrosis del tejido celular, especialmente de la región interescapular.

Recientemente se ha descrito un grupo heterogéneo aun no bien determinado como tal, el cual produciría una infección en lauchas jóvenes con lesiones especialmente de las visceras y con menos efecto sobre el sistema nervioso central o los músculos esqueléticos (11).

Cada uno de estos grupos, particularmente el A y B, que son los que han sido más extensamente estudiados desde un punto de vista general e inmunológico y sobre los cuales se posee hoy un conocimiento más completo, tienen un número grande de tipos an†igénicamente diferentes, cuya clasificación ha sido posible mediante el uso de las técnicas de: a) neutralización cruzada; b) desviación del complemento cruzada; c) test de protección cruzada en lauchas recién nacidas provenientes de madres vacunadas, $y$ d) test de protección cruzada en chimpancés con una infección subclínica (10).

Dalldorf ha clasificado las cepas por el aisladas y otras que ha tenido oportunidad de estudiar, mediante la designación de cada tipo antigénicamente diferente con un número de orden; así, por ejemplo, a los tipos del grupo A los designa por: tipos 1,2, pos del grupo A los designa por: tipos 1, 2, $3,4,5$, etc. $y$ en igual forma a los tipos del grupo B. Huebner y col. han estudiado también las relaciones inmunológicas, especialmente del grupo A en las cepas por él aisladas, designando a los tipos inmunológicamente diferentes por la letra $\mathbf{H}$ y asignando un número a cada tipo diferente; así, por ejemplo: $H_{1}, H_{2}, H_{4}$, etc. Sin embargo, ha sido la escuela de Melnick la que en este tipo de estudios inmunológicos más se ha destacado, en una excelente publicación de Contreras, Barnett y Melnick (12), estu- diando 232 cepas de virus $\mathrm{C}$ aisladas de diferentes partes de EE. UU. y de otros países, han logrado clasificar 16 tipos inmunologicamente diferentes, que han sido designados con el nombre de la cepa de origen.

Melnick y col, en los estudios histopatológicos realizados, no han logrado encontrar la alta especificidad de lesiones que han permitido a Dalldorf y Guifford separar los virus de grupos $\mathbf{A}$ y $\mathbf{B}$, razón por la que en su clasificación sólo hacen mención al tipo antigénicamente diferente, pero si para esclarecer mejor este problema, separáramos Ios 16 tipos de Melnick por grupos, de acuerdo a la clasificación hecha por Dalldorf, terndríamos una distribución como se aprecia en el cuadro $\mathrm{N}^{o} 1$.

Cuadro N? 1

Diniburion for givpo de to tipos antigeniomente diforentes nel uirth Coxmakiv

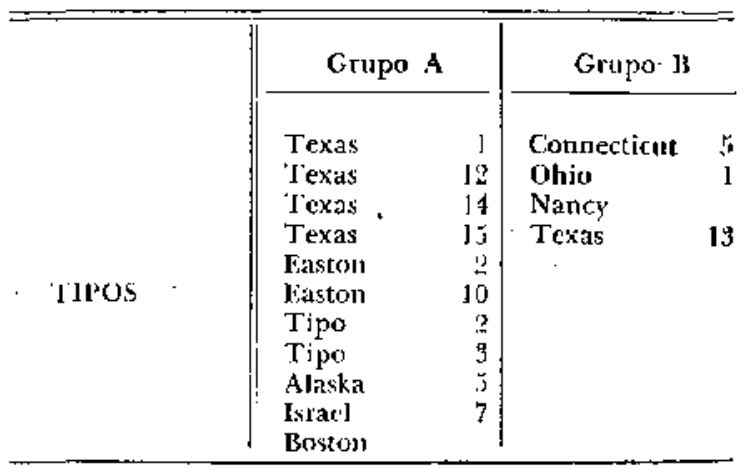

Cada uno de estos tipos antigénicamente diferentes que se han presentado en el cuadro inserto más arriba, poseen cepas semejantes en sus caracteres inmunológicos y no hemos querido hacer mención de ellas para no complicar el problema solamente.

Las pruebas realizadas con el virus Coxsackie tendientes a demostrar relaciones inmunológicas con otros virus, como los de Ia poliomielitis, encefalomielitis murina, parotiditis, herpes simple, corio meningitis linfocitaria, encefalomiocarditis, encefalomielitis venezolana $y$ enfermedad de New Castle, han sido totalmente negativos. Del mismo modo no ba sido demostrado el fenómeno de interferencia entre el virus Coxsackie $y$ el de la poliomielitis (10).

La respuesta inmunológica en humanos a la infección ha demostrado que los anticuerpos aparecen muy pronto en el curso de la infermedad. Así, por ejemplo, los anticuerpos neutralizantes de acuerdo a Melnick 
(10) sería posible detectarlos en la sangre circulante desde el primer día de enfermedad $\mathrm{y}$ ascienden rápidamente, en cambio, los anticuerpos fijadores del complemento comienzan a aparecer en la sangre periférica alrededor del $5^{\circ}$ día, llevando una curva de ascenso más lenta. El título de los anticlierpos neutralizantes alcanzaría su acmé entre el $1^{\circ}$ al 3.cr mes (30) y pueden ser detectados hasta los 2 años, en cuanto a los fijadores del complemento son más irregulares en llegar a su título máximo, siendo para algunos tipos más tardío (hasta. 3 meses) que en otros (31), lo cual es un factor de complicación en el estudio por este procedimiento con fines diagnósticos de algún cuadro clínico sospechoso, ya que el alza del título de anticuerpo por sobre cifras significativas, cual es la base para demostrar una infección en evolución, se hace muy tarde.

Dijimos al comienzo de esta exposición que en relación al aislamiento de estos microorganismos han sido varios los cuadros clínicos a los cuales se les ha querido atribuir especificidad en relación a la presencia de ellos y otros cuya interpretación a la luz del aislamiento ha sido muy difícil y ha complicado inmensamente el concepto que sobre ellos se tenía.

Haremos aquí solamente un breve resumen del aspecto clínico de los más importantes.

Probablemente uno de los cuadros mejor individualizados y cuya etiología obedece a virus Coxsackie es la angina herpética. Este cuadro clínico fué descrito por Zahorsky en 1920, pero sólo en 1950 Huebner y colaboradores lograron demostrar en una epidemia de una enfermedad febril entre niños de Parkwood, dentro del área metropolitana de Washington $D$. C., su etiología a virus Coxsackie.

Es una enfermedad benigna que se inicia con síntomas de compromiso general, dolor de cabera, a veces dolores difusos en el abdomen $\mathrm{y}$ extremidades, la temperatura suele elevarse durante los pródromos a $39,5^{\circ} \mathrm{C}$. y los pacientes acusan sensación de ardor en el paladar y garganta. Esta al comienzo se aprecia sólo ligeramente congestionada, simulando una faringitis banal. Al día siguiente de iniciada esta sintomatología el velo del paladar y los pilares anteriores del velo presentan unas manchitas rojas como pẹtequias, que rápidamente en el curso del día se transforman en pápulas y vesiculas, dentro de las 24 horas de aparecidas las vesículas, éstas se rompen, dejando una pequeña ulcerita de fondo rosado, rodeada de una aureola roja. Los síntomas generales $y$ la fiebre durante el período de erupción desaparecen $y$ la temperatura se normaliza dentro de las 72 horas de iniciada la enfermedad.

En los exámenes de laboratorio sólo el hemograma revela una ligera linfocitosis. Una vez que las lesiones han llegado a la fase de úlcera duran 2 días más para epitelizarse y volver a la normalidad.

El aislamiento reiterado del virus Coxsackie de estos enfermos, la ausencia del virus del herpes simple, asi como la demostración de anticuerpos para el virus $\mathrm{C}$ con un alza del título por sobre cifras significativas y funalmente, el estudio epidemiológico, permitjeron a Huebner y colaboradores (5) (17) (33) a través de una serie de publicaciones establecer que la etiología de esta enfermedad obedece a este nuevo grupo de virus, especialmente a Ios del grupo A de Dalldorf.

La búsqueda del virus en los enfermos sospechosos se hace por lavado bucal y en las deposiciones.

Otra enfermedad en la que se ha demostrado la presencia en las deposiciones del virus $C$ asi como una reacción inmunológica significativa en los enfermos y la ausencia de otros agentes causales es la "pleurodinia infecciosa", cuyo cuadro clínico es bien conocido. Varios autores han logrado establecer a través de estudios en brotes epidémicos las relaciones entre el vírus $\mathrm{y}$ la enfermedad, siendo tal vez Weller (15) y Lazarus (16) los que han reunido mayor experiencia en EE. UU. y Findlay y Howard (32) en Inglaterra.

Al lado de estos dos cuadros clínicos de más clara individualización, se han descrito una serie de otros, en los que se ha logrado el aislamiento del virus, aunque es todatía necesario una mayor experiencia en orden a esclarecer muchos puntos en los que la relación virus-enfermedad no-parece aún bien establecida. Así, pues, ya sea como infección espontánea o como accidente de laboratorio, se ha podido demostrar la pre sencia de estos virus en pacientes con un cuadro de "mialgias epidémicas", "gripe de verano", "fiebres o procesos febriles de etiolcgia desconocida", "meningitis asépticas". 
Un grupo importante de estas afecciones relacionadas con los virus Coxsackies son Jos cuadros clínicos semejante a la poliomielitis anterior aguda de forma paralítica o no paralítica y que han concentrado merecidamente la atención desde los primeros aislamientos de esta nueva especie de virus.

Dos problemas han surgido en relación a estos procesos: uno de ellos es la presencia df uno de los virus, el Coxsackie o el de la poliomielitis, en un enfermo, y segundo, la concomitancia de ambos virus en el mismo paciente. Desgraciadamente y por la muchas dificultades que esta clase de investigaciones tiene, no siempre ha sido posible investigar en un caso dado la presencia de ambos virus; por otra parte, cuando esto ha sido posible, el problema de interpretar estos resultados ha sido difícil, tanto por las posibilidades del rol patógeno como por las de poder ambos ser llevados por un portador.

Si en un enfermo con un proceso semejante al de la poliomielitis anterior aguda se aísla uno sólo de los dos virus (Coxsackie o poliomielitis) y se logra demostrar en la sangre de este enfermo un alza del título de anticuerpos por sobre cifras significativas, a la vez que por inoculaciones ty estudios serológicos se descarta la poliomielitis, no cabe duda. como lo ha demostrado Huebner (33), del rol patógeno del virus aislado, pero si se aislaran ambos virus en eI mismo enfermo, dos preguntas deben ser resueltas para la buena interpretación del estudio experimental:

$1^{\circ}$ Está la persona enferma por la acción de ambos virus o el cuadro sólo obedece a uno y el otro actúa sólo de tránsito?

$2^{\circ} \mathrm{Si}$ ambos están jugando un rol en el cuadro clínico, ¿cuál comanda los síntomas clínicos y cuál actúa como inaparente?

No hay duda que la demostración de los rnticuerpos homólogos en el curso de la enfermedad y en alza de título significativa, es decir, nunca inferior a cuatro veces el valor del título obtenido en la primera determinación, la cual debe hacerse precozmente en la fase aguda, es la base fundamental para esclarecer hoy en día el problema.

De acuerdo con Melnick (23 (38), mientras no se pruebe lo contrario, las manifestaciones paralíticas de los pacientes en los que se aíslen los dos virus, deben considerarse el resultado de la lesión del sistema nervioso central por el virus de la poliomielitis.
Melnick y Huebner (23) (33) (38) creen que actualmente hay evidencia que una infección doble sucede más frecuentemente como para ser considerada una mera coincidencia $y$ que en un terreno $y$ condiciones apropiadas, el virus Coxsackie puede actuar transformando una poliomielitis de forma no paralítica en paralítica.

Finalmente y para complicar aún más el problema, Melnick ha encontrado (24) en 2 casos por él estudiados una infección doble, en la que el virus de la poliomielitis aislado resultó ser de una virulencia muy baja, como fué posible demostrarlo por inoculación experimental y en la sangre de estos dos pacientes se pudo encontrar un alza significativa del título de anticuerpos para el virus Coxsackie, concluyéndose por esto que en estos 2 casos en referencia el cuadro clínico se debió a una infección por el virus Coxsackie.

No hay dudas por lo expuesto, por las innumerables dificultades de investigación en este terreno, y por la amplia y difundida ubicación de este nuevo grupo de virus, que aun después de 5 años desde su primer aislamiento $y$ de cientos de publicaciones al respecto, desde todos los puntos de vista, se está aún lejos de conocer su verdadero significado en muchas entidades clinicas, de las cuales se ha aislado y a las que se les ha querido encontrar en este nuevo grupo su agente etiológico.

Sin duda, mucho se ha logrado $y$ es inmensa la contribución que su aislamiento ha dado al mejor conocimiento de muchos procesos patológicos.

Los estudios en relación a la clínica y a la epidemiologia darán en definitiva su verdadero papel como agentes de tantos cuadros que hoy día forman parte del ya gran grupo de infecciones por virus de Coxsackie.

\section{Resımen}

El virus de Coxsackie o virus $\mathrm{C}$ fué aislado por primera vez por Dalldorf y Sickles y más tarde por Melnick, Shaw y Curnen de las deposiciones de niños que presentaron un cuadro clínico semejante al de la poliomielitis anterior aguda.

Posteriormente, Huebner lo aisló y estudió como agente etiológico de la angina herpética. Su rol como agente patógeno de la pleurodinia infecciosa $y$ de atros procesos fubriles agudos y epidémicos de etiología incierta como la gripe de verano, ha sido in- 
tensamente esludiado para establecer cuál es el verdadero papel del virus en ellas.

Su asociación con cuadros semejantes al de la poliomielitis anterior aguda ha sido también intensamente estudiado en orden a establecer su rol en estos procesos, pero aun él no ha sido definitivamente establecido.

Se trata de un grupo de virus de pequeño tamaño. que de acuerdo a Dalldorf se han arrupado en grupos A y B por las lesiones histopatológicas que determinan en la laucha lactante, que es su huésped más sensiblo. Posee numerosos tipos antigénicamente diferentes e innumerables cepas de cada uno de los tipos, entre las cuales se pueden establecer los fenómenos de inmunidad cruzados.

Los agentes externos actúan sobre ellos en forma variada, pero en general pueden resistir la acción de varios de ellos. Los antibióticos no actúan sobre ellos.

\section{BHALOGRAHA}

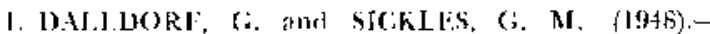
An Conilentifirl Filtroble: Agent Imblated fiam the Faces of Childten with P'aralyais fripoce los: Gl-6i2.

2. MELX゙ICK, J. I., SHAW, F. W. and C.lBNit,

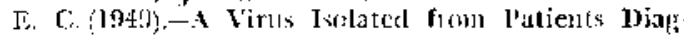
nosed as cion-t’ablytic bolionyelilis or Aseptic Meningitis. Proc. Soc Jixper. Biol. \& Merl. 7l: 341 . 340.

3. CIRNEN. F. C. (J950)-JUman IJisease Asociatad with the Coxsackic Viruses. Butl, New York tcad. Merl. 26: 395-342.

4. SHAW, F. W.; MFLNICK, J. I. and CITREN, k. C. (1950).-Iftection of Iaboratory tionkers with Coxsackic Virtses. Ann. Int. Mert. 39: 82.40.

B. HLEBNER. R. J.: COLE. R, M.: BLIMAN, F. A.: IBEI.L. J. A. ank] ['E.E.R.', T. 11. (195I)-Herpalugind. lidulogical Studies of a Specific lnfections Discasc. J. A. M. A. 145: $028-639$.

6 ZAHORSKY, I. (1920)-Herpetic Sote Ihroat. South. W. T. 13: 871.

7. ZIIIORSKY, J. (1924)--Herpangina (A sprcifir Disuser. Arch. Pediat. 41: $1 \mathrm{Al}$.

8. QLiCKI.liY, I. T. (1949)-CIItrafiltration and LItracentrifugation Studies of Coxsackic Viruses. Pres. Sor. lixper, Biol. \& Med. 72: 4\$4-435.

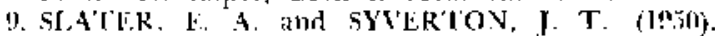
-Ty. Cilıvatiou of Coxsackie Vitcts. Proc. Soc. Fixper. Hiol. \& Med. 74: 509-510.

10. MELNIC,K, J. T, (1950)-Studies on Coxisackie Firuses lropertics. Imununological Asperes atul Distribalion in Nature. Bull. New Vork Acarl. Med. 26: $342-356$.

11. PAPIENHEIMLR, A. M.: MANILIS, T. B.; C.HFJVER, T. S, and WFLLIR. 7\% H. (1950).J.chions couscal in Sulkeling Wice by ceprain Vifuses Ischlaterl from ases of so called ntot Para-

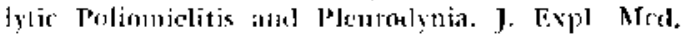
92: $169-190$.
12. CON'RERAS, G.; IBARNET'T, V. II. and MELNICK, J. I. (1952)-Identification of Coxsackic Viruses by Jummological Methods atkl theik Clasification into $] 6$ Antigenically Distint $\Gamma_{y} \mathrm{pes}$. J. $1 \mathrm{~mm}$, 60: $305-414$.

13. BRELFS, A.; BRlESE, S. S.; WARRFN, I. and HUEBSER, R. J. (1952)-Thysical l'topertics of two Group i Coxsackic (Herpangina) Viruscs when Propayated it liggs alud Mice as Delerinincel by iflatcentrifugation and lifertion $\mathrm{Mi}$. croscopy. J. Bact, 6t: 297-216.

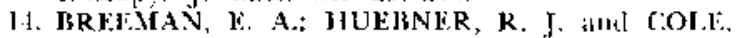
R. M. (I952)-S1udics of Coxsackic V'inusch. Iattoratory aspects of Ciroup A Viruses. An. J. Hyg. 5.5: $83-107$.

1.3. HLIJ.ER, 'I, H.: liNLERS, J. I\%; BLCKINGHAM, B. and FIN. J, J. (1950)-The tiolos) of Epiclemic Pleuromyia: A Study of two Viruses Isolated from a Typical Outbrak. J, of Imm. 65: $337 \cdot 340$.

13. I.ATARLS, A. S. JOHNSFOX, F.. A. and G.ALBRAITH, J. F. (19:52),-An Outbreak of Fpirle. mic Pleurorlynia with Special Reference to the Iaboratory Diagnosis of Coxsackie Viruses Infections, Am. J. Inul. Health. 42: 20-26.

17. HUEBNER, R, J.: ARWSlRONG, G,: RELMAN, E. A and COIE, R. M. (19\%0),-Stulies of Co:sackie Viruses, Prrtiminary Report on Occurren. re of Coxsackie Virus in a Solthern Masyland

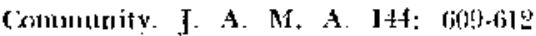

18. IIXN, T. J.: WELLER, T. II. and MOR(AIN, H. R, (t949)-Fpirlemic I'lesmolyua; Clinical atul Vijological Studies based on onc Hundrid and Fourecen cases. Arch. Int. Med. 83: 305-321.

10-CLRNLN, E. C.: SHAW, F. W. and MEINICK, f. L. (1949).-Discase Resembling Nom-Paralytic Polinmyclitis Associated with a Virls balhogenic fol Yutaut Mice. I. A. M. A. 141; $89+901$

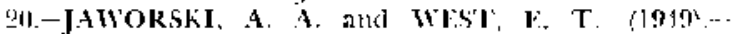
Aseptic Meningitis of Nvew linus oljgin. A $\mathrm{Se}$ rics of Fighteen cases. J. A. M. A. 141. Mu-phy.

2I. 1)ALLIOORE. (;.; SICKI.ES, (; M.: PLACFF, H. alut GIIIFORI). R. (I949).-A Vius Recon:uld from the leces of ['ulionyclitis Patients Patho. getnic for Suckling Mtice. J. [ixprel. Med. \&6: 50:$5 \mathrm{R} 2$.

2\%, CHFFVER, li. S:; DANIlis, J, B. and HFRSEY, F. F, (1950)-A Viral Ayent Joulated frons a Case of Non-Paralytic Poliomyelitis and pathog: nis for Suckling Mice: Its possible Relation to the Coxrackie Grump of Vimser. J. Exprtl. Mert. 92: $159-167$.

23. MFLNICK, J, l. and K.\{PLAN, A. S. (1950).-Dual Antiburly Response to Coxsuckie and $\mathbf{P}_{0}$ liomyclitıs. Viruses in Patients with Paralytic Poliomyelitis. Proc, Soc. Fxp. Biol. \& Med, 74: 81?. 81:\%.

g.t. MEINIC: J. I.; JLDINKO. N.: KAPLAN, -1. $S$ and KRAFT, I. M. (1949),-Ohio Strains of a Virus Pathogenic for Infant Mice (Coxsack: group). Simultaneous Occurrence with Polionyelitix Virus ils l'ationts with Summes Grippe. J. lixp. Med. 91; 185-195.

25. WFRR. G, H. and WOLEE, S. G. (1950)--ThrecDay Fever. An toute ficbrile viscase of Chillhood (Futher olbservations) with Virus Labolatory Studies and Isolation of the coxsackic Viras by liealtice I. Howitt. Ant. J. Dis. Child. 80; 21.258 


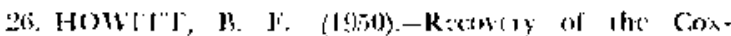
sackic group of Virust' fintu Human Sources.

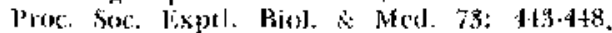

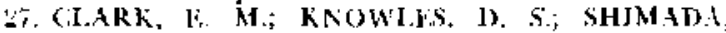

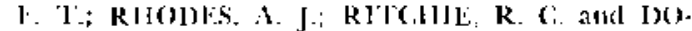

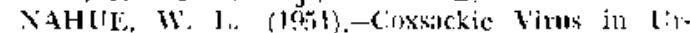
bate Seurage: Reconery of Viress in Seanom of lom

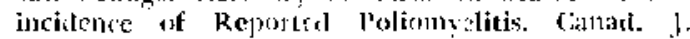
[ull. He;ilets. 19: loj:s:107.

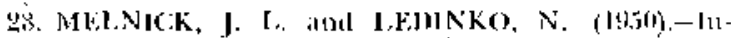
fection of commolgus Monikes with the Ohio

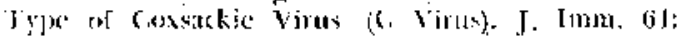
$1(1)-110$.

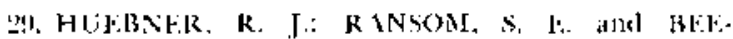
MAX. Ji. A. ([950),-sidedics of (ioxsakin Vinus. Aclaplation of a Strain to (hick fintryos. I'us's. Hoitlh. Rep. 6.8: Bo3-806.

90. MtLVICK, J. L. and LADNKO, N. (1650).-

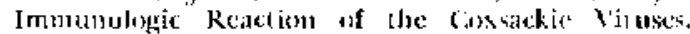

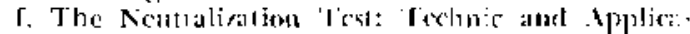
zion. J. lixp. Mfod. yja; $4635-182$.

31, KRAEI, I, M. and Mllivilik, J. l. (195il),Immunologic Reaction of the Coxeackie Virukes. 15. The Cimplement Fixalion Test. I. Hxp. Mod. 92: 493-495,

92. FINDLAY, (r, M. amel HOW'ARJ), E. M. (Bt50)... Coxsackie Viruses and Bomloslm Dis:ase, Brit. Meal. J. 1: 1299 .
33. GOI.F, R. M.; B]II.I, J. A.; BEENAN, ]i. A. an! HITBNER, R. J. (I 55 I).-Stuclics of Coxsackie Virluses: Obuntation on lipiclemiological Aspects of Croup at Vinuses. Am, J. Pub. Health, 41: $13 \cdot 19 \cdot 1354$.

34. MEI,NICK, J, J. and COISMAN, G, C, (195I).Jathogenesix of Goxackic Virnx lufectims. Multiplication of Visus and Evolution of the Muscle 1.esion in Mice. J. Iixprel. Acel. 9:5: 247.

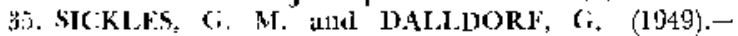
Serologic Difference among Strains of Coxsarkic Gouln of Vinuses. Iros: 5oc. Biol. \& Mcel. 72: 303.

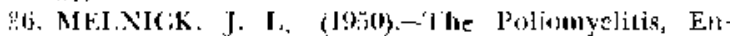
ceptalompocarditis ancl (axsackic Groul) of Vi. runes. Bact. Jor. 14: 238-24t.

37. AIFLXICK, J. Is; CIARKF, ‥ A. and KRAJT, I. M, (19:0),-listertunological Reactions of the Coxsackic Viruses, IIf. Crows-l'rotection Tests in Tufatt Mice Burn of Vaccinated Mothers. Transfes of Itumstuticy throught the Milk. J. Exptl. Med. (12: $190-\mathrm{i}(0)$.

38. SILLIN, S. A: MANIRL, G; P. and FARMER,

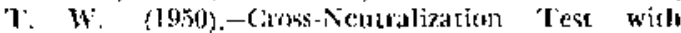
Coxsackie V'iruszs. Proc. Soc. Exp. Biol. \& Met. 73: $340 \cdot 341$.

88. MJINICK, I, I, amel (:LiRNLN, b. C, (1951)Pislionryelitis and Coxiskic Viruses in Paralytic loliomyclitis. l'udiatrics 8: 237-216. 